\title{
GENE FREQUENCIES IN BOSTON'S CATS
}

\author{
NEIL B. TODD* \\ The Biological Laboratories, Harvard University, Cambridge, Massachusetts 02138
}

Received 29.vi.63

\section{INTRODUCTION}

THREE previous papers have appeared on gene frequencies in domestic cat populations. These present data on the cats of London (Searle, I949), Mishima and Gotemba, Japan (Komai, I952), and Singapore (Searle, I959).

The genetic factors under consideration in the present study include black $\left(t^{y}\right) v s$. red $(y)$, a sex-linked pair of alternatives manifesting lack of dominance towards one another; agouti or tabby $\left(+^{a}\right)$ vs. self or non-tabby $(a)$; striped tabby $\left(+^{t}\right)$ vs. blotched tabby $\left(t^{b}\right)$; black and/or red $\left(+^{d}\right)$ vs. blue and/or cream dilution $(d)$; and dominant white $(W)$ vs. pigmented $\left(+^{w}\right)$. With the exception of the black-red alternatives the other factors are autosomal with presumably roo per cent. penetrance. In addition, some comments will be made on white spotting $(S)$, polydactyly $(P)$ and long-hair $(l)$. A comprehensive discussion of these characters will be found in Robinson (1 959).

\section{SAMPLE SOURCE}

The present sample represents stray or unwanted animals turned over to the Animal Rescue League (ARL) and the Angell Memorial Hospital, Massachusetts Society for the Prevention of Cruelty to Animals (MSPCA), Boston, Massachusetts; surgical and clinical cases at the MSPCA; and experimental animals at the Massachusetts General Hospital (MGH), Boston, Massachusetts. Two questions arose concerning the validity of considering these groups as a single population. The first was the possible selective destruction of cats at the MSPCA and the second concerned the cats of MGH which were supplied by a Rhode Island dealer some 50 miles south of Boston. The phenotypic distributions of the sex-linked alternatives black and red (table I) were used to compare these groups. No significant difference was found when all cats from ARL and MSPCA, with the exception of the morgue cats, were compared by a $\chi^{2}$ homogeneity test with the morgue cats $\left(\chi^{2}=0.34 ; 0.90>\mathrm{P}>0.75\right)$. A similar test comparing the MGH group to ARL and MSPCA also showed no significant difference $\left(\chi^{2}=\mathrm{I} \cdot \mathrm{I} 2 ; 0.75>\mathrm{P}>0.50\right)$.

Siamese and other obviously "fancy" cats were eliminated from this sample on the assumption that they do not share a common gene pool with it by virtue of their supervised breeding. This survey was carried out between May, I96i and January, I962.

- Present address: Animal Research Center, Harvard Medical School, Boston, Massachusetts 02115 . 
TABLE I

Distribution of black, tortoiseshell and red phenotypes among the sub-groups comprising the population under consideration. See text for discussion

\begin{tabular}{|c|c|c|c|c|c|c|c|c|}
\hline & & \multicolumn{3}{|c|}{ Females } & \multicolumn{2}{|c|}{ Males } & \multirow{2}{*}{$\begin{array}{l}\text { Unsexed or } \\
\text { Unclassified }\end{array}$} & \multirow{2}{*}{ Total } \\
\hline & & $+^{v}+v$ & $+y^{y} y$ & $y y$ & $+^{y}-$ & $y-$ & & \\
\hline ARL . & & I I & 8 & 2 & I I & 3 & 0 & 35 \\
\hline $\begin{array}{l}\text { MSPCA } \\
\text { (excluding }\end{array}$ & morgue) & 55 & 19 & o & 53 & I6 & 9 & $5^{2}$ \\
\hline $\begin{array}{l}\text { MSPCA } \\
\text { (morgue) }\end{array}$ & $\cdot \cdot$ & 18 & 9 & I & I 5 & 5 & I & 49 \\
\hline MGH & . & I8 & 12 & I & 20 & 4 & 8 & 63 \\
\hline Total & . & 102 & 48 & 4 & 99 & 28 & I8 & 299 \\
\hline
\end{tabular}

\section{RESULTS}

Sex distribution: among the sexed animals there were 160 females and 133 males. This distribution fits an expected $I: I$ with a probability of $10-20$ per cent. $\left(\chi^{2}=2 \cdot 4^{8}\right)$.

\section{TABLE 2}

Determination of randomness of breeding by comparison of theoretical distributions computed from gene frequencies with observed phenotype distributions

\begin{tabular}{|c|c|c|c|}
\hline & $\begin{array}{l}\text { Individuals } \\
\text { Observed }\end{array}$ & $y$ alleles & $\begin{array}{l}\text { Individuals } \\
\text { Expected }\end{array}$ \\
\hline $\begin{array}{l}+y+y \\
+y_{y} \\
y y \\
+y- \\
y-\end{array}$ & $\begin{array}{r}\mathrm{r} 02 \\
48 \\
4 \\
99 \\
28\end{array}$ & $\begin{array}{r}0 \\
48 \\
8 \\
0 \\
28\end{array}$ & $\begin{array}{r}\text { IOO.29 } \\
47.97 \\
5.74 \\
\text { I02.48 } \\
24.52\end{array}$ \\
\hline Total & $28 \mathrm{I}$ & 84 & \\
\hline
\end{tabular}

Gene frequencies: $y=0 \cdot 193$ and $+^{v}=0.807 ; \chi^{2}=1 \cdot 17 ; N=2 ; 0 \cdot 70>P>0.50$.

Randomness of breeding in this population was determined by the method employed by Searle (1949, 1959), i.e. calculation of the gene frequency of black $\left(+^{y}\right)$ and red $(y)$ in the population and comparison of the theoretical distribution of black, tortoiseshell and red phenotypes with the observed phenotype frequencies. These data are summarised in table 2. The correspondence of fit is $0.70>\mathrm{P}>0.50\left(\chi^{2}=1 \cdot 17\right.$; d.f. $=2$ ). The gene frequency for $y$ is 0.193 .

On the assumption that the population is random breeding the frequencies of the following alleles were calculated. 
Agouti (tabby) vs. self (non-tabby): Classification with respect to this character was not possible in dominant white individuals, some tortoiseshell females, and in animals with extreme white spotting. In addition red individuals were rejected because of the epistasis of red to the agouti self alternatives. The total classified was 238 , of which 98 were self $(a a)$. Therefore, the combination frequency (c.f.) is $a a=0.4 \mathrm{I}^{2}$ and the gene frequency (g.f.) is $a=0.64^{2}$, and $+^{a}$ $=0.35^{8}$. These data are summarised in table 3 .

Striped vs. blotched tabby: Classification for these alternatives was not possible in many non-tabby individuals as the homozygous recessive condition at the agouti, self locus is generally epistatic to the striped or blotched pattern. However, so-called "ghost" markings were visible in some self individuals and where striped could be distinguished

TABLE 3

Phenotype frequencies and gene frequencies of agouti, tabby, blue dilution and dominant white. There are no significant differences between males and females in the distributions of any pair of alternatives

\begin{tabular}{|c|c|c|c|c|c|c|}
\hline Allele & Females & Males & Unsexed & Total & $\begin{array}{c}\text { Combination } \\
\text { Frequency }\end{array}$ & $\begin{array}{c}\text { Gene } \\
\text { Frequency }\end{array}$ \\
\hline$+^{a}$ & 78 & 60 & 2 & 140 & 0.588 & 0.358 \\
$a$ & 61 & 35 & 2 & 98 & 0.412 & 0.642 \\
$t^{t}$ & 64 & 68 & 3 & 135 & 0.804 & 0.557 \\
$t^{b}$ & 15 & 18 & 0 & 33 & 0.196 & 0.443 \\
$t^{d}$ & 126 & 105 & 3 & 234 & 0.818 & 0.574 \\
$d$ & 28 & 21 & 3 & 52 & 0.182 & 0.426 \\
$W$ & 6 & 76 & 0 & 13 & 0.044 & 0.022 \\
$t^{w}$ & 154 & 126 & 6 & 286 & 0.956 & 0.978 \\
\hline
\end{tabular}

from blotched the animals were classified. Cats with extensive white spotting and some tortoiseshells could not be classified. In addition 6 animals had patterns not clearly classifiable as striped or blotched. A third dominant allele at this locus, Abyssinian $\left(t^{L}\right)$ was not present. The total classified was therefore 168 . Among these animals 33 were blotched tabbies $\left(t^{b} t^{b}\right)$. Therefore, c.f. $t^{b} t^{b}=0 \cdot 196$, g.f. $t^{b}=0 \cdot 443$, and $+^{t}=0.557$ (table 3$)$.

Black and/or red $v s$. blue and/or cream dilution: Only the dominant white cats could not be classified with respect to this character. From a total of 286 animals classified, 52 individuals were dilute $(d d)$. Therefore, c.f. $d d=0.182$, g.f. $d=0.426$, and $+^{d}=0.574$ (table 3 ).

Dominant white vs. pigmented: All cats (299) were classified according to this character. Two individuals had a small patch of pigmented hair, greyish to black in appearance on the top of the head. This is attributed, on the basis of independent breeding evidence, to incomplete penetrance of dominant white rather than to a spotting allele. There were 286 pigmented individuals. Therefore, c.f. $+^{w}+{ }^{w}=0.95^{6}$, g.f. $+^{w}=0.978$, and $W=0.022$ (table 3 ). 
Dominant white spotting $v s$. non-spotted: No effort was made to distinguish between the degrees of spotting present. As some of the animals classified were surgical cases viewed in cages, it was not possible to examine them for distribution of spotting. The figures given here therefore, are minimum values for spotting. Dominant white individuals were not classified leaving a total of 286 of which $9 \mathrm{I}$ were classed as non-spotted. Therefore, c.f. $+^{s}+t^{s}=0.318$, and g.f. $l=t^{s}=0.564$, and $S=0.436$.

Short hair vs. long hair: Among 249 animals classified for hair length 25 were long haired. Therefore c.f. $l l=0 \cdot 09 \mathrm{I}$, and g.f. 0.302 .

Linkage: Linkage between two mutant alleles would not of necessity be detectable through comparison of predicted and actual simultaneous occurrence based on combination frequencies of individual mutants in a population (Robinson, 1959). The number of markers is yet too limited to detect loose linkages in small samples, and the ratios of recombinant alternatives in a population might obscure any linkage. As a matter of curiosity dilute was compared with long hair and polydactyly, and the predicted and expected values for simultaneous occurrence concurred closely.

\section{DISCUSSION}

In comparing the Boston population to those of London, Singapore and Mishima, a number of interesting points are noted. The gene frequencies of mutants in these populations are summarised in table 4 .

TABLE 4

Frequencies of non-wild type alleles in four cat populations. See text for discussion

\begin{tabular}{|c|c|c|c|c|}
\hline Allele & Boston & London & Singapore & Mishima \\
\cline { 3 - 5 }$y$ & & & & \\
\cline { 3 - 4 } & 0.19 & 0.10 & 0.31 & 0.39 \\
$a$ & 0.64 & 0.76 & 0.60 & 0.79 \\
$t^{\mathrm{L}}$ & 0.000 & 0.002 & 0.23 & $\ldots$ \\
$d$ & 0.44 & 0.81 & 0.11 & $\ldots$ \\
$W$ & 0.43 & 0.14 & 0.13 & $\ldots$ \\
$S$ & 0.022 & 0.004 & 0.012 & 0.015 \\
& 0.44 & $0.3^{b}$ & 0.50 & $\ldots$ \\
\hline
\end{tabular}

The gene frequency for red in Boston stands between that of London and Singapore, differing significantly from both $\left(\chi^{2}=19.7\right.$ and ${ }_{15} .8$ respectively). Beyond saying that the frequency of this allele may vary widely (perhaps due to human preference, Searle, I959) the interpretation of these differences is open to speculation. Searle (r959) suggests that the incidence of red increases from Western Europe to Eastern Asia. Whether Boston fits into this cline by virtue of nonEnglish contributions or differs because of some local pressure remains to be seen.

The incidence of the self (non-tabby) allele in Boston's population 
is high, as in the case in London, Singapore and Mishima. In the combination frequency of self, both Boston and Singapore (which do not differ significantly from one another) differ significantly from London and Mishima (between which there is no significant difference). Such comparisons, however, are complicated by the fact that the expression of tabby $\left(+^{t}, t^{b}\right)$ is independent of the condition of the agouti, self locus in a red animal. Hence the phenotype frequency of tabby will be dependent upon the gene frequency of red. Therefore, the differences between Boston and Singapore on the one hand and London on the other will be accentuated while the apparent correspondence of London and Mishima will be minimised. A further consequence of the expression of tabby in all red individuals is that the frequency of tabby among males may be significantly higher than in females, e.g. in Boston the phenotype frequency of non-tabby in females is 0.42 while in males it is $0 \cdot 28$. Nevertheless, it appears that the agouti, self-alternatives have little differential advantage under a wide range of environmental situations.

In contrast to the relatively uniform distribution of agouti and self, the striped, blotched and Abyssinian alternatives are very different. Especially interesting is the low frequency of blotched tabby $\left(t^{b}\right)$ in Boston compared to London. The combination frequency difference is highly significant $\left(\chi^{2}=88 \cdot 5\right)$. This is a second indication that Boston's cat population is unrelated to that of London, although not necessarily to England, as Searle (personal communication) has suggested that London may be atypical for England. Clarification of these differences must await sampling of other English and American cities and repetition of the survey of London to ascertain whether the frequency of $t^{b}$ is increasing, decreasing, or static.

The frequency of $d$ dilution is remarkably high in Boston. This may be due to human selection, since so-called "Maltese" cats appear to be popular with the local citizenry. This factor and polydactyly, also locally prized, are the only characters noted which distinguish Boston clearly from all other cities yet studied.

\section{SUMMARY}

A group of 299 cats from Boston, Massachusetts and vicinity were found to represent a random breeding population. The gene frequencies of eight mutants were computed. Differences and similarities between this population and those of London, Singapore and Mishima, Japan are discussed.

\section{REFERENCES}

комAI, T. 1952. Incidence of the genes for coat color in Japanese cats. Annot. Zool. Faponenses, 25, 209-2II.

Robinson, Roy. 1959. Genetics of the domestic cat. Bibliographia Genet., 8, 273-362. SEARLE, A. G. 1949. Gene frequencies in London's cats. Four. Genet., 49, 2 14-220. SEARLE, A. G. 1959. A study of variation in Singapore cats. Four. Genet., 56, I I I-I 28. 